ture by environment and on heredity. Fo example, we might expect increased webbing of the feet, and this might become hereditary.

Hiram M. Stanley.

LAKE FoREst, ILL., June.

\section{DARKENING OF THE CATHODE IN A} CROOKES TUBE.

A PEAR-SHAPED Crookes tube with a cathode disc in its narrow end has been used extensively by us during the past ten weeks in private experimentation and in public lectures on Röntgen rays. In common with many other experimenters, we have observed that after much usage the glass opposite the cathode disc and the glass about the anode became darkened. But we do not recall having seen any statement recorded regarding the darkening of the cathode disc. When we began using the tube the surface of the aluminium disc was uniformly bright throughout; now there is on the surface facing the broad end of the tube a dark brown ring concentric with the disc. This ring has an internal diameter of about $6 \mathrm{~mm}$., and is darkest near its inner edge, the densest portion being, perhaps, $1 \mathrm{~mm}$. across. Outside of this darkest portion the ring fades off gradually toward the outer edge of the disc. Taken as a whole, the internal and external diameters of the ring are about $5 \mathrm{~mm}$. and $11 \mathrm{~mm}$. respectively. The circular area inside of the dark ring is the brightest part of the disc. The diameter of the disc is about $17 \mathrm{~mm}$.

During the discharge through the tube we now observe what we did not notice before, viz., a pencil of faint bluish light emanating from the circular area of the disc inside the dark ring. The pencil is normal to the disc. The light resembles the blue or purplish light about the anode. The cylindrical pencil is most distinct at the disc and gradually fades away and becomes invisible at a distance from it of about 2 or $3 \mathrm{~cm}$. If, by reversal of the current, the disc is made the anode, then the pencil of blue light cannot be seen, but almost the entire tube is filled with the same purplish light. Sometimes this purplish light fills the tube also when the disc is used as a cathode. In such cases the discharge at the spark gap (placed in series with the tube) is fat and noisy; the tube shows very little fluorescence and the radiation of Röntgen rays is greatly diminished.

FLORIAN CAJORI, William Strieby, Colorado College, Colorado Springs.

\section{SCIENTIFIC LITERATURE.}

Voice Building and Tone Placing, showing a method of relieving injured vocal cords by tone exercises. By H. Holbrook Curtis, Pн. B., M. D. D. Appleton and Company. 1896.

This latest claimant for favor in the difficult field of voice production will be found to contain much that is old to those familiar with the subject of acoustics and some that is as unexpected as it is new. The struggling pupil will find it difficult to extract the pearl of good advice from the shell of lengthy discussion. From the preface one can see that the author realizes at once the difficulty of the problem and what its solution should be, but it is doubtful if he has fulfilled the promise.

The author begins with a brief outline of the history of music, which is followed by a description of the anatomy of the larynx which is naturally all right, until he begins to discuss the operation of the various parts, and here certain discrepancies arise. For example, we are told that there is but one register, or rather that registers are 'fallacies,' and yet in attempting to discuss our control of pitch he refers to reaching a 'stage in the production of the lower register,' where, 'for any other further elevation of pitch, a complete rearrangement of the vocal apparatus is necessary.' Just exactly what the devotees of registers claim. In point of fact, however, if one has the proper use of the voice, the same muscles control the pitch from lowest to highest, without break or interruption.

The above is an example of the uncertainty in which the reader is left; registers are called fallacies, and yet they are discussed at length ; they are assumed to exist and their fundamental differences in mechanism pointed out. Another statement which is very misleading, to say the least, is that air pressure in the lungs affects the pitch of the tone; "the pitch of the tone depends upon the strength of the expiratory pressure." How can we then take a tone 
piano, swell it to forte and diminish it again, without getting off the pitch?

In regard to respiration an elaborate discussion leaves one in doubt as to what method to use, unless it be a slightly amplified natural breathing, which is, of course, correct. The author seems an advocate of 'chest resonance' as being very efficacious, whereas, in fact, it is extremely difficult to see how vibrations in a closed cavity of constantly changing volume can be called resonance or can reinforce a tone. A cavity to reinforce a tone must have a definite volume and opening; it must be open to the air, else how could its resonance increase the intensity of the tone outside?

Vocal resonators and their importance are well emphasized and treated, except for the inclusion of the sinuses, antra and chest among the reinforcing cavities. The latter part of this chapter is especially good.

Under 'tones and overtones' a deal of acoustics is introduced which ought to be free from such ideas as that "a simple fundamental tone is not known in music," or that " there are also lower partials or undertones."

The chapter on registers is very peculiar and inconsistent, and some remarkable ideas as to the mutual action of the vocal cords and resonant cavities are put forward which will scarcely receive the approval of physicists, even though supported by a mass of supposed evidence furnished by the stroboscope. The author is continually referring to the voice as if it were the result of reeds or membranes. The voice has a mechanism to control the length, tension and weight of the vocal cords; these are the factors which control the pitch of a string. The overtones in the voice belong to the series in which the first overtone is twice the rate of the fundamental, the second three and so on. This is the series of string overtones. The pitch of a reed depends upon its length, thickness and elasticity; the larynx has no means of varying such factors. The series of overtones given by a reed is different from that experimentally found in the voice.

We are thus forced to consider the vocal apparatus as a stringed instrument. Under tone placing we find Dr. Curtis' specialty, 'nodules of attrition' and their cure. His idea is that the cords rub together, irritating each other, tearing each other, and even forming callous nodules. These he removes in a few hours by simple exercises. Other throat specialists have not observed these phenomena; and indeed how shall we believe a ragged or callous vocal cord could be cured by any exercises in a few hours. These ideas are fortified with numerous cuts of photographs of the vocal cords that associate none too well with the author's caustic remarks about touching up photographs to meet 'preconceived requirements.' Some of the advice given in this chapter is, however, worthy of approval.

It is rather remarkable that, after an elaborate discussion of the larynx, and breathing and the rest, the author should quote with evident approval Jean de Reske's epigrammatic statement that, 'la grande question du chant devient une question du nez.' All we can do with the nose is to leave it open.

The chapter on voice building doubtless contains many good exercises and much good advice, inspired as it was by such a master of tone production as Madame Melba. The concluding chapter on voice figures contains numerous pretty pictures and interesting matter which is, however, foreign to the subject of the book.

There is much that is good in the book, but a desire to give a full discussion often leaves one in serious doubt as to the correct conclusions and renders it difficult for a novice to discriminate between the good and the bad.

\section{W. HALLOCK.}

\section{Grundriss der Krystallographie für Studirende und} zum Selbstunterricht. By Dr. Gottlob Linck, Professor of Mineralogy at the University in Jena. Jena, Gustav Fischer. 1896. $8^{\circ}$. VI. and 255 pp. 2 colored plates and 482 figs.

Although the best treatises in crystallography are to be found in the German language, elementary text-books on the subject are as rare in Germany as in England or America. It is true that in nearly all books on mineralogy the principles of crystallography are discussed to some extent; and that occasionally the discussion is of value to the student. But in the great majority of cases it serves merely to bother him and to give him a distaste for that 